\title{
Peer Tutoring for Anatomy Workshops in Cambodia
}

Kylie Pickles ${ }^{1}$, Jason J. Ivanusic ${ }^{2}$, Junhua Xiao², Callum Durward ${ }^{3}$, Andrea Burke Ryan ${ }^{4}$, Jennifer A. Hayes ${ }^{2 *}$

${ }^{1}$ School of Medicine, Faculty of Health, Deakin University, Waurn Ponds, Victoria, Australia

${ }^{2}$ Department of Anatomy and Neuroscience, School of Biomedical Sciences, University of Melbourne, Victoria, Australia

${ }^{3}$ Department of Dentistry, Faculty of Health Sciences (Dentistry), University of Puthisastra, Phnom Penh, Cambodia

${ }^{4}$ Department of Nursing, Faculty of Health Sciences, University of Puthisastra, Phnom Penh, Cambodia

Running title: Anatomy workshops in Cambodia

*Correspondence to: Assoc. Prof. Jenny Hayes, Department of Anatomy and Neuroscience, University of Melbourne, Parkville, VIC 3010, Australia. E-mail: j.hayes@unimelb.edu.au

Grant sponsor: American Association of Anatomists, Bethesda, MD;

Grant name: Education Outreach Grant

ABSTRACT

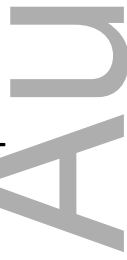

This is the author manuscript accepted for publication and has undergone full peer review but has not been through the copyediting, typesetting, pagination and proofreading process, which may lead to differences between this version and the Version of Record. Please cite this article as doi: $\underline{10.1002 / a s e .1804}$

This article is protected by copyright. All rights reserved 
Historical loss of staff and teaching resources in Cambodia has resulted in significant challenges to anatomy education. Small group anatomy teaching opportunities are limited. A visit to Cambodia by a teaching team from the University of Melbourne in 2010 demonstrated it was possible to implement well-resourced anatomy workshops for this purpose. However, continuation of the workshop program was inhibited by the limited number of local teaching staff. In 2015 another team from the University of Melbourne returned to Cambodia to implement anatomy workshops that incorporated peer tutoring. The objective was to improve teacher-to-student ratios and demonstrate that interactive anatomy workshops could be delivered successfully despite low staff numbers. The anatomy workshops were attended by 404 students of Medicine, Dentistry, Nursing and Midwifery at the University of Puthisastra. Medical students were invited to act as peer tutors for nursing students. A five-point Likert scale questionnaire was used to determine student satisfaction with both the workshops and peer tutoring. The overwhelming majority were positive about the workshops and keen for them to continue. Almost all medical students who acted as peer tutors agreed or strongly agreed that this role increased their anatomical knowledge (98\%) and confidence (94\%). Most nursing students agreed or strongly agreed with statements that they would like peer tutoring to continue (94\%) and that they would like to be peer tutors themselves (88\%). This report demonstrates that peer tutoring could be an effective tool in educational settings where poor staff-to-student ratios limit delivery of interactive workshops.

Key words: gross anatomy education, health professions education, anatomy workshops, interactive workshop, peer tutoring, higher education, Cambodia.

\section{INTRODUCTION}

Very few health care professionals survived the Khmer Rouge period in Cambodia (1975-1979). This resulted in a severe shortage of trained health care providers. Over the past 20 years the Cambodian Ministry of Health has been addressing this shortage through policy development and planning (Koto-Shimada et al., 2016) as well as the provision of scholarships for overseas education of health professionals. Despite this there are still only 0.2 doctors and 0.9 nurses and midwives per 1,000 population which puts Cambodia well below the World Health 
Organization's critical shortage threshold of 2.28 doctors, nurses and midwives per 1,000 population (Kanchanachitra et al., 2011). This impacts on the delivery of health care services and the availability of qualified personnel to teach students of these professions. The destruction of teaching resources and facilities by the Khmer Rouge has also resulted in major hurdles to the delivery of an international standard of education at Cambodian universities (Barras et al., 2010).

While development of a skilled workforce has been recognized as a priority by the Cambodian Government, an increase in popular demand for higher education has exceeded the State's funding resources. Consequently growth in higher education has largely been through the development of privately financed universities that rely almost exclusively on student fees to fund their courses (Vicheth and Soveacha, 2013). By international standards these student fees are very low resulting in limited income for universities and subsequently low budgets for expenditure on staffing and teaching resources.

Other developing countries face similar challenges in providing education for health care professionals (Murray et al., 2011). Difficulties in providing enough adequately trained staff to teach anatomy have been reported in several countries (Memon, 2009; Johnson et al., 2012), and there are also documented reductions in teaching hours for anatomy as well as limited access to cadavers for dissection (McCuskey et al., 2005; Turney, 2007; Drake et al., 2009; Sugand et al., 2010). In Cambodia these challenges have resulted in a preference for anatomy being taught in didactic lecture settings to large classes. All Cambodian students entering a Bachelor degree in medicine, nursing or dentistry undertake a Foundation year of core science subjects including anatomy. The anatomy teaching in the Foundation year comprises 45 hours of anatomy, taught to large groups of students as lectures and provides a general overview that is systems-focused. From year 2 onwards, the anatomy teaching varies by discipline. Dentistry students have a further 45 hours of anatomy teaching while medical students complete a further 90 hours. Nursing students have an additional 90 hours of an integrated program of anatomy and physiology. The course content at this level is generally systems-focused, with 
some regional anatomy. Preference across the entire program is for didactic teaching of large groups of students because it represents a large cost saving for the universities. The students are provided with hard copies of the power-point presentations delivered in this large group setting. They may be referred to the library to look at anatomy textbooks, however it is rare for students to buy their own. Many of the lecturers in anatomy are surgeons or specialists in other areas of medicine. Most health science students at the different universities have little if any exposure to dissection and students do not have access to prosections. Every university has a basic set of anatomical models and bones, as prescribed by the Ministry of Health, however when these are used in a large class lecture setting, their value is limited. There is little practical component and few small group activities. Assessment is through quizzes, assignments and a final written examination, which is mostly multiple-choice questions.

Inclusion of a workshop program within an anatomy curriculum is desirable as the educational benefits of anatomy workshops are well documented. Nicholson and colleagues demonstrated that by attending an interactive, multi-modal anatomy workshop, students of the health sciences showed significant improvements in their examination performance (Nicholson et al., 2016). Similarly Scott and colleagues demonstrated improvements in examination performance for students who attended anatomy workshops compared with those who did not (Scott et al., 2017). Improvements were found to be significantly greater for students who attended multiple workshops. A similar association between practical class attendance and improvements in anatomy assessment was also reported by Gonsalvez et al. (2015). In 2010 a team of anatomy educators from the University of Melbourne demonstrated it was possible to implement wellresourced anatomy workshops in Cambodia. A series of workshops was designed and delivered for dental and medical students at The University of Health Science and the International University in Phnom Penh (Hayes et al., 2011). The program provided interactive anatomy workshops which covered all systems/regions of the body using teaching resources which were available in Cambodia or which were readily transportable from Australia. These included anatomical models, flagged photographic images, X-rays, body-paints and clinical examination equipment. Feedback from these workshops indicated that the Cambodian students greatly valued the workshops and were keen for this style of anatomy teaching to be continued. The 
success of this program showed that it was possible to deliver interactive anatomy workshops using available resources without the use of human material which is largely unavailable for teaching purposes in Cambodia. However the workshop program was not continued due to the limited availability of local teaching staff.

In 2015 the Melbourne University anatomy teaching team was invited to collaborate with the University of Puthisastra in Cambodia to deliver another series of interactive anatomy workshops. In order to facilitate the sustainability of the workshops as part of ongoing anatomy education it was considered essential to incorporate a peer tutoring element in the workshop program. Peer tutoring is a well-established educational tool to enhance student learning and reduce pressure on limited numbers of teaching staff (Durán et al., 2012; Johnson et al., 2012; Manyama et al., 2016). Peer tutoring is an educational arrangement in which one student teaches one or more fellow students and it can be implemented in several different forms. Peer tutoring or reciprocal peer tutoring occurs when the student teacher and the students are at an equal stage of training, while near peer tutoring uses more progressed students to instruct less advanced students (Evans and Cuffe, 2009). Herrmann and colleagues also described the use of peer teaching in a multidisciplinary setting involving medical and nursing students studying anatomy (Herrmann et al., 2015). This arrangement provided an additional opportunity for inter-professional education to occur alongside learning of the subject matter. The potential learning gains from peer tutoring are considerable. Studies from a variety of settings indicate that student tutors report increased self-confidence, improvements in knowledge retention and development of communication skills (Benware and Deci., 1984; Nnodim, 1997; Nelson et al., 2013). Communication and teaching skills may be further enhanced if training is provided for student tutors (Menezes et al.,2016; Burgess et al.,2017). Students who receive tutoring from peers also report improvements in understanding, interpersonal skills and study habits. (Lockspeiser et al., 2008; Manyama et al., 2016)

In addition to the reported benefits of peer tutoring there are numerous accounts of improved learning outcomes for students who participate in workshops designed for active learning 
(Gonsalvez et al., 2015; Bruno et al., 2016; Saavedra et al., 2016; Scott et al., 2017). Active learning aims to enable students to participate in a range of activities designed to help them think critically about the content and apply it to real life situations. A variety of innovative methods for promoting active learning have been implemented in anatomy workshops. Naug and colleagues used plasticine modelling while Massey trialed the use of clay to assist students to develop a greater understanding of the musculoskeletal system (Naug et al., 2011; Massey, 2014). Shigeoka and colleagues found assisting students to create string muscle models helped to reinforce their understanding of the relationship between structure and function (Shigeoka et al., 2000). In the Cambodian workshops a variety of interactive learning activities such as body painting, examination of models, completion of worksheets and clinical examination techniques were used to facilitate active learning and encourage student engagement and enquiry.

The objective of the collaboration, which is reported here, was to demonstrate that the delivery of interactive anatomy workshops is feasible in educational settings with low numbers of teaching staff through the implementation of a peer tutoring program. In addition, this novel approach to the employment of peer tutoring was assessed to determine whether previously reported benefits of peer tutoring, such as increased tutor confidence and enhanced communication skills were realized in this setting. Measuring student gains in knowledge following delivery of this series of anatomy workshops was not assessed as part of this study.

\section{MATERIALS AND METHODS}

In November 2015, six anatomy educators from the University of Melbourne spent one week at the University of Puthisastra. This included a preliminary briefing of course coordinators and four days of anatomical workshops, one for each of the medical, midwifery, nursing and dental student cohorts. These students had all completed at least one year of their Health Science course including study with their Khmer teachers on the relevant anatomy being covered in the workshops. At the start of each session a lecture covering content relevant to the workshop was delivered in English and translated by local student interpreters. The workshops each ran 
for two hours and consisted of four stations which utilized models, photographs, posters and body paints. The workshops were supported by comprehensive worksheets and staffed by University of Melbourne staff assisted by local students who acted as interpreters. Their primary role was to facilitate the students' interactions with the workshop notes and resources. Details of each workshop, including the specific resources and the student cohort that attended are presented in Table 1. Each two-hour workshop was repeated four times per day. On completion of the workshops all students who attended were surveyed to determine their satisfaction with the workshop style of learning anatomy.

The first day of workshops covered cardio-respiratory anatomy and was attended by the medical student cohort. On completion of these sessions the medical students were invited to return to act as peer tutors for the same cardio-respiratory workshop being attended by nursing students two days later. Due to time constraints there was no opportunity to provide additional training for the volunteer peer tutors. Two thirds of the medical students agreed to participate as peer tutors. This enabled the nursing students to attend the cardio-respiratory workshops with the addition of peer tutors. A significant advantage of this arrangement was the ability of the peer tutors to provide information for the nursing students in the Khmer language. On conclusion of each of these workshops both the peer tutors and the nursing students completed questionnaires to evaluate their experience with peer tutoring. Attendance at the workshops and completion of the survey was voluntary and anonymous. This study was approved by the University of Melbourne Human Ethics Research Committee (Ethics ID: 1545746.1)

All questionnaires utilized a five-point Likert scale to evaluate agreement with statements regarding the student experience of either the workshops or peer tutoring (strongly agree $=5$ and strongly disagree $=1$ ), or the value of the different types of learning materials presented (very helpful = 5 and not at all helpful $=1$ ). Questions were written to reflect qualitative observations that the students could easily provide feedback on in a short time frame at the end of each session (See Supplementary Material Appendix for questionnaires). Students were 
also given the opportunity to provide open feedback. GraphPad Prism, version 5.0a (GraphPad Software, Inc., La Jolla, CA) was used for statistical analyses of Likert scale data. Descriptive statistics were used to summarize the responses to each question provided by each student cohort (mean \pm standard deviation). A Kruskal-Wallis Analysis of Variance (KW ANOVA; with Dunn's post-hoc testing) was used to determine if there were significant differences between groups of students. This is a non-parametric alternative to an ANOVA for comparing data from three or more independent groups (Altman, 1991). Non-parametric statistics were used because Likert scale data are ordinal. An alpha level of $5 \%$ was used for all statistical significance testing ( $P<0.05$ denotes statistical significance).

The survey tool used was validated using SPSS statistical package, version 25 (IBM Corp., Armonk, NY). Questions were split into four scales/constructs: (1) statements regarding the student experience of the workshops, (2) value of the different types of learning materials presented, (3) statements regarding the experience of the peer tutors, and (4) statements regarding the experience of students that received peer tutoring. Cronbach's alpha was used to measure internal consistency (reliability). It is used to determine if questions in a single scale are indeed capturing the same construct. Cronbach's alpha coefficients greater than 0.80 indicate high levels of internal consistency, whereas values less than 0.65 suggest that individual items should be deleted to examine whether consistency improves. Kendall's tau-b (tb) correlation coefficient is a nonparametric measure of the strength and direction of association that exists between two variables measured on an ordinal scale (especially when there is a small sample size with many tied ranks) and was used to assess the validity of the questions in each scale. A positive tb indicates agreement among students in answering each of the questions and is presented with a hypothesis test to determine significance with an alpha level of $P<0.05$ as above.

RESULTS

\section{Validation of the survey tool}

This article is protected by copyright. All rights reserved 
Kendall's tau B and Cronbach's alpha were used to assess the validity and internal consistency (reliability) of the survey tool, respectively. Cronbach's alpha analysis revealed that questions in the scales relating to the student experience of the workshops (Cronbach's alpha $=0.74$ ), the value of the different types of learning materials (Cronbach's alpha $=0.7$ ), and the experience of nursing students who received peer tutoring (Cronbach's alpha $=0.7$ ) were all internally consistent (reliable). It also revealed a high level of internal consistency for questions in the scale relating to the experience of the peer tutors (Cronbach's alpha $=0.85$ ). Kendall's tau B analysis revealed a statistically significant, positive correlation between all pairwise question comparisons in the scales relating to the student experience of the workshops $\left(\tau_{\mathrm{b}}>0.2, P<\right.$ $0.01)$, the value of the different types of learning materials $\left(\tau_{b}>0.37, P<0.01\right)$ and the experience of nursing students who received peer tutoring $\left(\tau_{\mathrm{b}}>0.16 P,<0.05\right)$. There was also a positive correlation between all pairwise question comparisons in the scale relating to the experience of the peer tutors $\left(\tau_{b}>0.13\right)$, but the small sample size $(n=36)$ precluded statistical significance for all comparisons in this scale.

\section{Evaluation of the workshops}

A total of 404 students attended the anatomy workshops. This included 54 medical, 68 midwifery, 187 nursing and 95 dentistry students. The response to the workshops was overwhelmingly positive with $96 \%$ of all students indicating they agreed or strongly agreed that they would "like more workshop style of teaching" (mean \pm SD $=4.33 \pm 0.6)$. This positive response was consistent across all four student cohorts with no statistical difference between any groups determined (KW ANOVA, $P>0.05$, Table 2). The responses also indicated that the majority of students believed that the workshops helped them to learn new facts (mean \pm SD $=$ $4.1 \pm 0.7$ ), understand the three-dimensional structure of the body (mean $\pm S D=4.1 \pm 0.6$ ), and understand difficult concepts in anatomy (mean \pm SD $=4.12 \pm 0.6$ ). Medical and dental students consistently rated these learning benefits of the workshops more highly than nursing and midwifery students and in most cases the differences were statistically significant (KW ANOVA, $\mathrm{P}<0.05$, Table 2). Students responded favorably to the teaching and learning resources provided as demonstrated in Table 3. Dental students reported that the use of anatomical models was 
more helpful for their learning than any of the other cohorts (KW ANOVA, $P<0.05$ ). Medical students reported that body painting was more helpful for their learning than any of the other cohorts (KW ANOVA, P<0.05).

\section{Evaluation of peer tutoring}

Almost two thirds of the medical students who attended the first workshop volunteered to act as peer tutors for the nursing students. Feedback obtained from these students after they acted as peer tutors indicated strong support for the peer tutoring program (Figure 1). Their responses showed they not only enjoyed their experience of being a tutor, but also that they perceived benefits of increased anatomical knowledge (98\% agreed or strongly agreed, mean $\pm S D=4.66 \pm 0.1)$ and confidence ( $94 \%$ agreed or strongly agreed, mean $\pm S D=4.39 \pm 0.1)$ due to their participation in the program. Ninety seven percent of the Cambodian peer tutors agreed or strongly agreed that they would like the opportunity to do more peer tutoring (mean $\pm S D=$ $4.58 \pm 0.1$ ) and that this could be to any student group if they received some prior instruction (mean $\pm \mathrm{SD}=4.47 \pm 0.1$ ). This was supported by open comments such as: "I feel happy when I can teach. I am so excited I can have this experience, I hope I can teach like this again".

Feedback was also solicited about perceptions of the peer tutoring from the nursing students who received the peer instruction. Their responses indicated that the large majority of these students found the peer tutoring to be a positive experience (Figure 2). Most nursing students agreed or strongly agreed with statements that they would like peer tutoring to continue $194 \%$,

mean $\pm S D=4.26 \pm 0.04)$ and that they would like to be peer tutors themselves $(88 \%$, mean $\pm S D$ $=4.18 \pm 0.05)$. Most had confidence in the peer tutors as a source of information $(84 \%$, mean $\pm S D=3.94 \pm 0.04)$ and reported finding it easier to ask questions of the peer tutor $(74 \%$, mean $\pm S D=3.81 \pm 0.05)$. This was supported by open comments such as "I want to study with peer tutor more because they provide me with a lot of knowledge."

\section{Open feedback}

This article is protected by copyright. All rights reserved 
Comments in the open feedback section were provided by up to one quarter of the students surveyed. Comments about the workshops were both positive and negative. The most common comments related to student enjoyment ( $n=18 / 404$; e.g., "I did enjoy doing the workshop a lot"), requests for return visits and/or ongoing workshop-style teaching (n=98/404; e.g., "I really like workshops because make me understand a lot. I want this again") and improved anatomical knowledge and understanding ( $=33 / 404$; e.g., "I realized I have learned a lot n. from them. Their explanations are clear including photograph pictures, models, etc."). Some students suggested that language was a barrier ( $\mathrm{n}=3 / 404$; e.g., "I like your workshop style teaching but its difficult for me to listen to your pronunciation."). Open feedback provided by medical student peer tutors supported the notion that they enjoyed peer tutoring $(n=9 / 36)$ and that they would like to do it again $(n=9 / 36)$. Open feedback provided by nursing students who received the peer tutoring supported the notion that they would like to have more workshops with peer tutors $(n=29 / 187)$.

\section{DISCUSSION}

The main findings of the present study indicate that peer tutoring is a feasible method to facilitate delivery of anatomy workshops in resource poor situations such as in Cambodia, and that students with different backgrounds (medicine, dentistry, nursing and midwifery) can appreciate the value of anatomical workshops presented in this setting. There is great potential in Cambodia for the implementation of interactive anatomy workshops to enhance delivery of current anatomy curricula, however this may be impeded by limited availability of staff. The workshop series described here demonstrated that the use of peer tutors can overcome this impediment. Incorporating medical students as peer teachers within the anatomy workshops provided additional instructors for the nursing students. Improving staff-to-student ratio with little additional cost is a major advantage of this intervention and could be useful in any educational setting where staff numbers and resources are limited. The ratio of staff-tostudents in anatomy subjects at the University of Puthisastra varies across disciplines and cohorts. Nursing, midwifery and dentistry students have staff-to-student ratios between 1:30 to 1:60. Medical classes range in size from 60 to 110 students each year. However, the larger 
classes are divided into two groups of up to 55 students in each. Following the success of the peer tutoring described here and the positive feedback from students, the School of Dentistry have now introduced peer-based learning and more small group teaching into their anatomy curriculum. In addition, recent restructuring at the University of Puthisastra has included a review of teaching in the basic medical sciences, including anatomy, and there is a willingness to introduce a greater range of learning strategies and more small group activities.

Utilizing medical students to teach nursing students also encourages communication and collaboration across these disciplines. Inter-professional education can help to develop teamwork and respect across disciplines and may therefore lead to potential long term gains in health care (Gill et al., 2006). Both the Cambodian medical and nursing students were positive about their experiences of peer tutoring. Their feedback supported findings from other studies where students who acted as peer tutors reported improved confidence, greater knowledge retention, enhanced communication skills and development of leadership qualities (Qureshi and Stormyhr, 2012; Kim, 2015; Reyes-Hernández et al., 2015). Krych and colleagues reported similar benefits following the use of peer tutoring specifically in anatomy dissection classes (Krych et al., 2005). In their study, student tutors reported increased understanding of topics, greater retention of information and enhanced communication skills. These are all desirable attributes for students of the health professions to develop. Increasingly the importance of developing communication and teaching skills for medical students is being recognized. Teaching is a key activity for health professionals in their work with students, colleagues and patients and these skills are becoming part of required graduate attributes for medical students (Dandavino et al., 2007; van Diggele et al., 2015). Consequently training programs for medical students acting as peer teachers are being developed and delivered. In 2008 Soriano and colleagues conducted a survey of 130 MD degree-granting U.S. schools. Of the ninety-nine respondents $44 \%$ provided training for peer teachers to develop their teaching skills (Soriano et al., 2008). It has been reported that student tutors who complete a teaching skills training session feel more confident to facilitate small group workshops and provide feedback (Nestel and Kidd, 2002). While recognizing the potential benefits of providing training for peer tutors

This article is protected by copyright. All rights reserved 
the time constraints of the series of workshops delivered in Cambodia prevented additional training sessions from being implemented. Providing training for peer tutors in the future could further develop their skills and preparedness for this role.

Students who have received peer tutoring also report learning benefits which include improvements in their understanding, interpersonal skills and study habits (Manyama et al., 2016). This may be due to increased motivation and ease of communication with the peer tutors due to a reduction in the cognitive congruence gap (Ten Cate and Durning, 2007). Improvements in examination performance following implementation of peer teaching have also been demonstrated (Youdas et al., 2008; Nicholson et al., 2016), but we did not explore assessment outcomes in our study.

\section{Limitation of the study}

There are some limitations of this study. Due to time constraints, specific training sessions for peer tutors were impractical, and no attempt was made to assess student gains in knowledge following delivery of workshops. Language was sometimes a barrier to effective communication, but this was overcome in part by utilizing Cambodian students with a good grasp of English as translators.

\section{CONCLUSION}

The data collected during the week of anatomy workshops at the University of Puthisastra indicate that peer tutoring is an effective and feasible method to facilitate anatomy workshops in resource poor situations. The enthusiasm of the Cambodian students for continued peer tutoring suggests this will be an effective method to enable the ongoing delivery of interactive anatomy workshops at the University of Puthisastra. The successful implementation of this anatomy workshop program and the benefits reported by the participants indicate that it is an effective approach for educational situations where poor staff-to-student ratios limit delivery of interactive workshops. 


\section{SUPPLEMENTARY MATERIAL: APPENDIX}

1. Student Perception Questionnaire

2. Peer tutoring Questionnaire

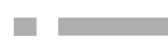

The authors would like to acknowledge the support by the American Association of Anatomists (AAA) for their grant supporting this project. The authors would like to thank the Department of Anatomy and Neuroscience (University of Melbourne) for supporting this teaching trip. The authors also thank Mentone Educational Supplies of Melbourne, Australia who provided models and posters to enhance the interactive anatomy workshops. An oral presentation of this report was delivered during the 2016 Australian and New Zealand Association of Clinical Anatomists Conference.

\section{NOTES ON CONTRIBUTORS:}

KYLIE PICKLES, B. App. Sc. (Osteo.), is an associate lecturer in anatomy and physiology in the School of Medicine, Faculty of Health at Deakin University, Geelong Waurn Ponds Campus, Victoria, Australia, where she teaches anatomy to first- and second-year post-graduate medical students. At the time of this study she was a senior anatomy tutor in the Department of Anatomy and Neuroscience, School of Biomedical Sciences at the University of Melbourne, Parkville, Australia.

JASON J. IVANUSIC, Ph.D., is an associate professor in the Department of Anatomy and Neuroscience, School of Biomedical Sciences at the University of Melbourne, Parkville, Australia. He teaches anatomy and neuroscience to post-graduate medical, dental and 
physiotherapy students, undergraduate science and biomedicine students and has research interests in understanding the neurobiology of pain.

JUNHUA XIAO, M.B.B.S., Ph.D., is a senior lecturer in the Department of Anatomy and Neuroscience, School of Biomedical Sciences at the University of Melbourne, Parkville, Australia with over 15 years experience in biomedical research, in particular neurobiology. She teaches topographic anatomy and neuroscience to both postgraduate and undergraduate science and biomedical students. Her skills in research have been recognized with awards and project grants at both national and international levels.

CALLUM DURWARD, B.Sc., B.D.S., M.D.Sc., D.Com.H., M.P.H., F.R.A.C.D.S., is Dean of the Faculty of Health Sciences (Dentistry) at the University of Puthisastra, Phnom Penh, Cambodia, and adjunct professor at James Cook University in Australia. He is a specialist pediatric dentist and has a long history in supporting third world dentistry. His research interests include health sciences education, early childhood caries, and dental public health.

ANDREA BURKE RYAN, R.N., M.H.Sc. (HONS.) Nursing, is the Head of Department of Nursing at the University of Puthisastra in Phnom Penh, Cambodia. She earned her Bachelor in Nursing degree from the Auckland University of Technology and her Master Health Science degree in Nursing from the University of Auckland. She has over 40 years nursing experience with 15 years in nursing education.

JENNIFER A. HAYES, M.B.B.S., is an associate professor of topographic anatomy in the Department of Anatomy and Neuroscience, School of Biomedical Sciences at the University of Melbourne, Parkville, Australia with over 25 years' experience in curriculum design and implementation for undergraduate and postgraduate science, biomedicine, medicine, physiotherapy and surgical anatomy students. Her skills in teaching and engagement have been recognized with awards at both institutional and national levels. 


\section{LITERATURE CITED:}

Altman DG. 1991. Practical Statistics for Medical Research. $1^{\text {st }}$ Ed. London, UK: Chapman and Hall. 624 p.

ㅁ.

Barras C, Durward C, Hong S. 2010. Anatomy education in a developing country: A lecture and dissection program in Phnom Penh, Cambodia. Clin Anat 23:338-351.

Benware CA, Deci EL. 1984. Quality of learning with an active versus passive motivational set. Am Educ Res J 21:755-765.

Bruno PA, Love Green JK, Illerbrun SL, Holness DA, Illerbrun SJ, Haus KA, Poirier SM, Sveinson KL. 2016. Students helping students: Evaluating a pilot program of peer teaching for an undergraduate course in human anatomy. Anat Sci Educ 9:132-142.

Burgess A, Roberts C, van Diggele C, Mellis C. 2017. Peer teacher training (PTT) program for health professional students: Interprofessional and flipped learning. BMC Med Educ 17:239.

Dandavino M, Snell L, Wiseman J. 2007. Why medical students should learn how to teach. Med Teach 29:558-565.

Drake RL, McBride JM, Lachman N, Pawlina W. 2009. Medical education in the anatomical sciences: The winds of change continue to blow. Anat Sci Educ 2:253-259.

Durán CE, Bahena EN, Rodríguez Mde L, Baca GJ, Uresti AS, Elizondo-Omaña RE, López SG. 2012. Near-peer teaching in an anatomy course with a low faculty-to-student ratio. Anat Sci Educ 5:171-176.

This article is protected by copyright. All rights reserved 
Evans DJ, Cuffe T. 2009. Near-peer teaching in anatomy: An approach for deeper learning. Anat Sci Educ 2:227-233.

Gill D, Parker C, Spooner M, Thomas M, Ambrose K, Richardson J. 2006. Tomorrow's doctors and nurses: Peer assisted learning. Clin Teach 3:13-18.

Gonsalvez DG, Ovens M, Ivanusic J. 2015. Does attendance at anatomy practical classes correlate with assessment outcome? A retrospective study of a large cohort of undergraduate anatomy students. BMC Med Educ 15:231.

Hayes JA, Ivanusic JJ, le Roux CM, Hatzopoulos K, Gonsalvez D, Hong S, Durward C. 2011. Collaborative development of anatomy workshops for medical and dental students in Cambodia. Anat Sci Educ 4:280-284.

Herrmann G, Woermann U, Schlegel C. 2015. Interprofessional education in anatomy: Learning together in medical and nursing training. Anat Sci Educ 8:324-330.

Johnson EO, Charchanti AV, Troupis TG. 2012. Modernization of an anatomy class: From conceptualization to implementation. A case for integrated multimodal-multidisciplinary teaching. Anat Sci Educ 5:354-366.

Kanchanachitra C, Lindelow M, Johnston T, Hanvoravongchai P, Lorenzo FM, Huong NL, Wilopo SA, dela Rosa JF. 2011. Human resources for health in Southeast Asia: Shortages, distributional challenges, and international trade in health services. Lancet 377:769-781

Kim MM. 2015. Peer tutoring at colleges and universities. Coll Univ 90:2-7.

This article is protected by copyright. All rights reserved 
Koto-Shimada K, Yanagisawa s, Boonyanurak P, Fujita N. 2016. Building the capacity of nursing professionals in Cambodia: Insights from a bridging programme for faculty development. Int J Nurs Prac 22:S22-S30.

Krych AJ, March CN, Bryan RE, Peake BJ, Pawlina W, Carmichael SW. 2005. Reciprocal peer teaching: Students teaching students in the gross anatomy laboratory. Clin Anat 18:296-301.

Lockspeiser TM, O'Sullivan P, Teherani A, Mulle J. 2008. Understanding the experience of being taught by peers: The value of social and cognitive congruence. Adv Health Sci Educ Theory Pract 13:361-372.

Manyama M, Stafford R, Mazyala E, Lukanima A, Magele N, Kidenya BR, Kimwaga E, Msuya S, Kauki J. 2016. Improving gross anatomy learning using reciprocal peer teaching. BMC Med Educ 16:95.

Massey K. 2014. Clay modeling of the musculoskeletal system: Does active learning increase retention and comprehension. In: Proceedings of the Interdisciplinary STEM Teaching \& Learning Conference (STEM 2014); Statesboro, GA, 2014 March 7-8. Poster 35. Georgia Southern University, Statesboro, GA. URL: http://digitalcommons.georgiasouthern.edu/stem/2014/2014/35 (accessed 4 March 2018).

McCuskey RS, Carmichael SW, Kirch DG. 2005. The importance of anatomy in health professions and the shortage of qualified educators. Acad Med 80:349-351.

Memon IK. 2009. Anatomy education faces challenges in Pakistan. Anat Sci Educ 2:193-194.

Menezes A, Burgess A, Clarke AJ, Mellis C. 2016. Peer-assisted learning in medical school: Tutees' perspective. Adv Med Educ Pract 7:31-38.

This article is protected by copyright. All rights reserved 
Murray JP, Wenger AFZ, Downes EA, Terrazas SB. 2011. Educating Health Professionals in LowResource Countries. A Global Approach. The Carter Center. $1^{\text {st }}$ Ed. New York, NY: Springer Publishing Company, LLC. 42 p. URL:

https://www.cartercenter.org/resources/pdfs/news/health publications/ephti/ephtibookpreface.pdf (accessed 4 March 2018).

Naug HL, Colson NJ, Donner DG. 2011. Promoting metacognition in first year anatomy laboratories using plasticine modeling and drawing activities: A pilot study of the "blank page" technique. Anat Sci Educ 4:231-234.

Nelson AJ, Nelson SV, Linn AM, Raw LE, Kildea HB, Tonkin AL. 2012. Tomorrow's educators ... today? Implementing near-peer teaching for medical students. Med Teach 35:156-159.

Nestel D, Kidd J. 2002. Evaluating a teaching skills workshop for medical students. Med Educ 36:1094-1095.

Nicholson LL, Reed D, Chan C. 2016. An interactive, multi-modal anatomy workshop improves academic performance in the health sciences: A cohort study. BMC Med Educ 16:7.

Nnodim JO. 1997. A controlled trial of peer-teaching in practical gross anatomy. Clin Anat 10:112-117.

Qureshi MA, Stormyhr E. 2012. Group dynamics and peer-tutoring a pedagogical tool for learning in higher education. Int Educ Stud 5:118-124.

Reyes-Hernández CG, Carmona Pulido JM, De la Garza Chapa RI, Serna Vázquez RP, Alcalá Briones RD, Plasencia Banda PM, Villarreal Silva EE, Jacobo Baca G, de la Garza Castro O, Elizondo Omaña RE, Guzmán López S. 2015. Near-peer teaching strategy in a large human anatomy course: Perceptions of near-peer instructors. Anat Sci Educ 8:189-193. 
Saavedra MA, Villaseñor-Ovies P, Harfush LA, Navarro-Zarza JE, Canoso JJ, Cruz-Domínguez P, Vargas A, Hernández-Díaz C, Chiapas-Gasca K, Camacho-Galindo J, Alvarez-Nemegyei J, Kalish RA. 2016. Educational impact of a clinical anatomy workshop on 1st-year orthopedic and rheumatology fellows in Mexico City. Clin Rheumatol 35:1299-1306.

$$
\square
$$

Scott J, Louw G, Kahn D. 2017. The value of supplementary anatomy workshops for improving undergraduate performance. S Afr J Surg 55:46-49.

Shigeoka CA, Bavis RW, Seveyka J. 2000. Teaching musculoskeletal anatomy: A technique for active learners. Am Biol Teach 62:198-201.

Soriano RP, Blatt B, Coplit L, Cichoski Kelly E, Kosowicz L, Newman L, Pasquale SJ, Pretorius R, Rosen JM, Saks NS, Greenberg L. 2010. Teaching medical students how to teach: A national survey of students-as-teachers programs in U.S. medical schools. Acad Med 85:1725-1731.

Sugand K, Abrahams P, Khurana A. 2010. The anatomy of anatomy: A review for its modernization. Anat Sci Educ 3:83-93.

Ten Cate O, Durning S. 2007. Peer teaching in medical education: Twelve reasons to move from theory to practice. Med Teach 29:591-599.

Turney BW. 2007. Anatomy in a modern medical curriculum. Ann R Coll Surg Engl 89:104-107.

van Diggele C, Burgess A, Mellis C. 2015. Teacher training program for medical students: Improvements needed. Adv Med Educ Pract 6:265-270.

Vicheth SEN, Soveacha ROS. 2013 Anatomy of Higher Education Governance in Cambodia. Working Paper Series No. 86. $1^{\text {st }}$ Ed. Phnom Penh, Cambodia: CDRI. 25 p. 
Youdas JW, Hoffarth BL, Kohlwey SR, Kramer CM, Petro JL. 2008. Peer teaching among physical therapy students during human gross anatomy: Perceptions of peer teachers and students. Anat Sci Educ 1:199-206.

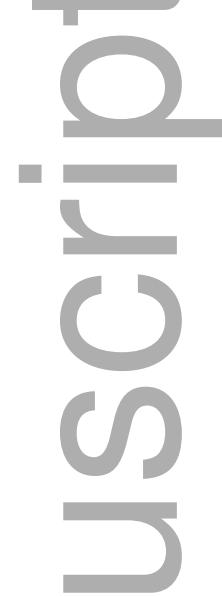

FIGURE LEGENDS

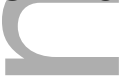

Figure 1. Perceptions of peer tutoring by medical student tutors. Number of respondents $n=$ 34; answers were reported on a five-point Likert scale: Strongly agree $=5$; Agree $=4 ;$ Neutral $=$ 3; Disagree $=2$; Strongly disagree $=1$. Error bars represent Mean \pm Standard deviation.

Figure 2. Perceptions of peer tutoring by nursing student tutees. Number of respondents $n=$ 187; answers were reported on a five-point Likert scale: Strongly agree= 5; Agree = 4; Neutral = 3; Disagree $=2$; Strongly disagree $=1$ Error bars represent Mean \pm Standard deviation .

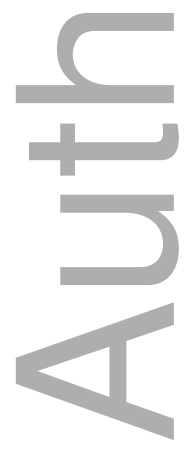

This article is protected by copyright. All rights reserved 
Table 1. Anatomy Workshop details

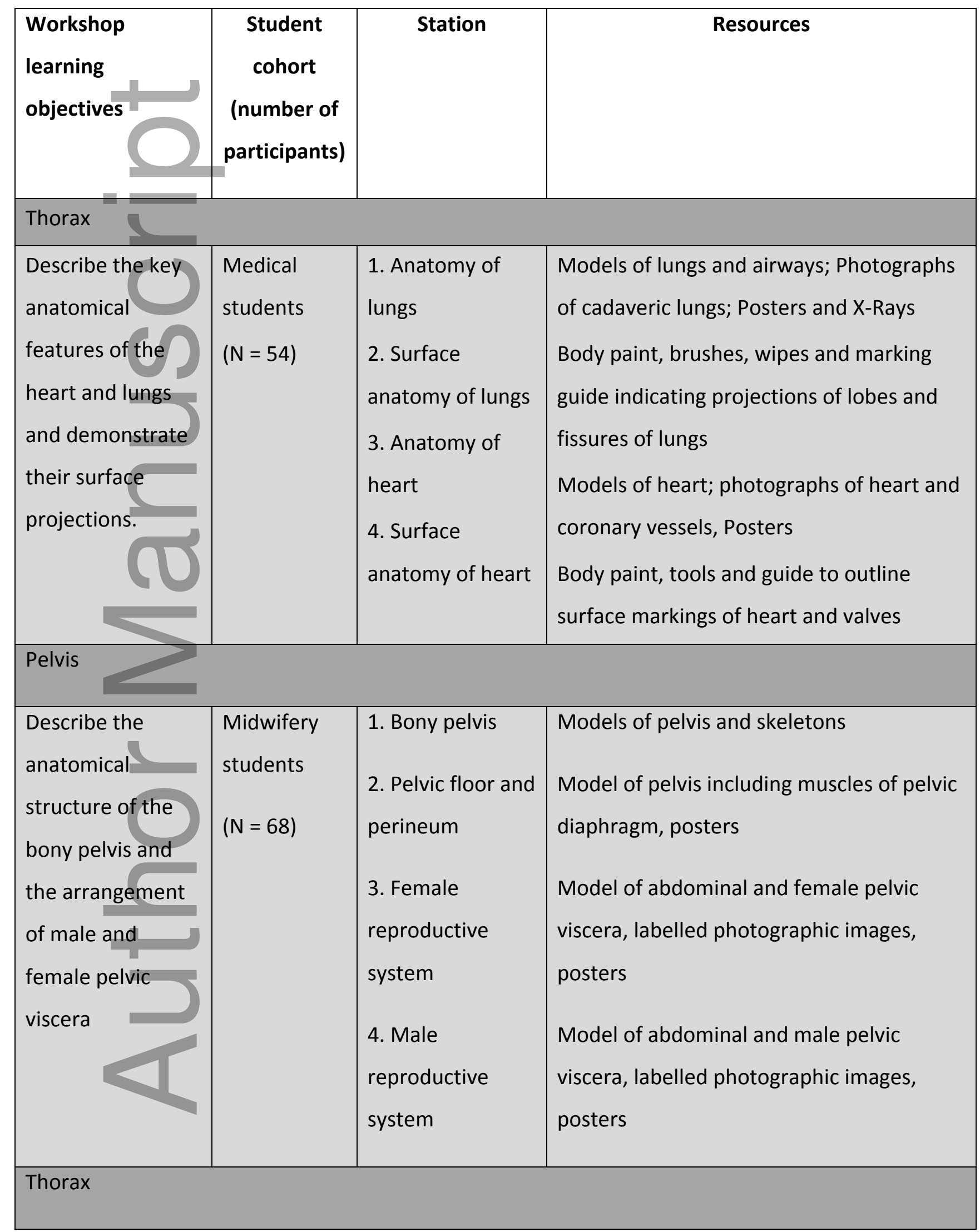

This article is protected by copyright. All rights reserved 


\begin{tabular}{|c|c|c|c|}
\hline $\begin{array}{l}\text { Describe the key } \\
\text { anatomical } \\
\text { features of the } \\
\text { heart and lungs } \\
\text { and demonstrate } \\
\text { their surface } \\
\text { projections. }\end{array}$ & $\begin{array}{l}\text { Nursing } \\
\text { students } \\
(\mathrm{N}=187)\end{array}$ & $\begin{array}{l}\text { Repeat of Thorax } \\
\text { workshop for } \\
\text { medical students } \\
\text { with addition of } \\
\text { peer tutors }\end{array}$ & $\begin{array}{l}\text { As described for thorax workshop for } \\
\text { medical students }\end{array}$ \\
\hline Skull, Nasal Cavit) & nd Face & & \\
\hline $\begin{array}{l}\text { Identify key } \\
\text { anatomical } \\
\text { features of the } \\
\text { skull, face, nasal } \\
\text { and oral cavities. } \\
\text { Demonstrate the } \\
\text { surface marking of } \\
\text { key facial } \\
\text { structures. }\end{array}$ & $\begin{array}{l}\text { Dental } \\
\text { students } \\
(\mathrm{N}=95)\end{array}$ & $\begin{array}{l}\text { 1. Skull } \\
\text { 2. Nose, mouth, } \\
\text { and larynx } \\
\text { 3. Face, scalp, } \\
\text { and parotid gland } \\
\text { 4. Surface } \\
\text { anatomy of face }\end{array}$ & $\begin{array}{l}\text { Models of skull and photographic images, } \\
\text { head and neck model } \\
\text { Photographic images, X-rays, CT scans, } \\
\text { posters, pen light to examine oral cavity. } \\
\text { Model of head, photographs of specimens } \\
\text { Body paint, brushes, wipes and guide to } \\
\text { mark surface projections of muscles, } \\
\text { parotid gland, facial nerve and paranasal } \\
\text { sinuses. }\end{array}$ \\
\hline
\end{tabular}


Table 2 - Student perceptions of workshops

\begin{tabular}{|c|c|c|c|c|c|}
\hline J & $\begin{array}{l}\text { Medicine } \\
(n=54) \\
\text { Mean ( } \pm S D)\end{array}$ & $\begin{array}{l}\text { Dentistry } \\
(n=95) \\
\text { Mean ( } \pm S D)\end{array}$ & $\begin{array}{l}\text { Nursing } \\
(n=187) \\
\text { Mean ( } \pm \text { SD) }\end{array}$ & $\begin{array}{l}\text { Midwifery } \\
\qquad(n=68) \\
\text { Mean ( } \pm S D)\end{array}$ & $\begin{array}{c}\text { Statistical } \\
\text { difference at } \\
\text { P }<0.05\end{array}$ \\
\hline $\begin{array}{l}\text { I would like more workshop- } \\
\text { style teaching }\end{array}$ & $4.48( \pm 0.50)$ & $4.42( \pm 0.61)$ & $4.25( \pm 0.61)$ & $4.29( \pm 0.49)$ & $\begin{array}{c}\text { no } \\
\text { differences }\end{array}$ \\
\hline $\begin{array}{l}\text { The workshops helped me } \\
\text { understand difficult concepts } \\
\text { in anatomy }\end{array}$ & $4.37( \pm 0.56)$ & $4.17( \pm 0.81)$ & $4.03( \pm 0.61)$ & $4.10( \pm 0.43)$ & $\begin{array}{l}\text { D vs N, } \\
\text { Md vs. N, } \\
\text { Md vs. Mw }\end{array}$ \\
\hline $\begin{array}{l}\text { The workshops helped me } \\
\text { understand the 3-dimensional } \\
\text { structure of the body }\end{array}$ & $4.30( \pm 0.54)$ & $4.16( \pm 0.51)$ & $4.02( \pm 0.58)$ & $3.90( \pm 0.58)$ & $\begin{array}{l}\text { D vs. Mw, } \\
\text { Md vs. Mw, } \\
\text { Md vs. N }\end{array}$ \\
\hline $\begin{array}{l}\text { I learned new facts in the } \\
\text { workshop }\end{array}$ & $4.41( \pm 0.66)$ & $4.20( \pm 0.61)$ & $3.95( \pm 0.68)$ & $4.12( \pm 0.50)$ & $\begin{array}{l}\text { D vs. N, } \\
\text { Md vs. N, } \\
\text { Md vs. Mw }\end{array}$ \\
\hline $\begin{array}{l}\text { The worksheet was helpful in } \\
\text { my understanding of anatomy }\end{array}$ & $4.40( \pm 0.57)$ & $4.22( \pm 0.64)$ & $4.11( \pm 0.64)$ & $4.10( \pm 0.60)$ & $\begin{array}{l}\text { Md vs. N, } \\
\text { Md vs. Mw }\end{array}$ \\
\hline
\end{tabular}

Mean $( \pm S D)$ of student responses for each statement assessed using five-point Likert scale (Strongly agree $=5 ;$ Agree $=4 ;$ Neutral $=3 ;$ Disagree $=2 ;$ Strongly disagree $=1$ ). Md, medical cohort; D, dentistry cohort; $\mathrm{N}$, nursing cohort; Mw, midwifery cohort. 
Table 3. Student perceptions of learning materials

\begin{tabular}{|c|c|c|c|c|c|}
\hline Resource & $\begin{array}{l}\text { Medicine } \\
\qquad(n=54) \\
\text { Mean ( } \pm S D)\end{array}$ & $\begin{array}{c}\text { Dentistry } \\
\text { (n= 95) } \\
\text { Mean ( } \pm S D)\end{array}$ & $\begin{array}{c}\text { Nursing } \\
\text { (n= 187) } \\
\text { Mean ( } \pm \text { SD) }\end{array}$ & $\begin{array}{l}\text { Midwifery } \\
\qquad(n=68) \\
\text { Mean (士SD) }\end{array}$ & $\begin{array}{c}\text { Statistical } \\
\text { difference at } \\
\mathrm{P}<0.05\end{array}$ \\
\hline Photographs & $4.34( \pm 0.56)$ & $4.43( \pm 0.60)$ & $4.34( \pm 0.58)$ & $4.40( \pm 0.49)$ & $\begin{array}{c}\text { no } \\
\text { differences }\end{array}$ \\
\hline Models & $4.36( \pm 0.59)$ & $4.57( \pm 0.58)$ & $4.18( \pm 0.68)$ & $4.31( \pm 0.50)$ & $\begin{array}{l}\text { D vs. Mw, } \\
\text { D vs. N }\end{array}$ \\
\hline Body painting & $4.72( \pm 0.45)$ & $4.48( \pm 0.62)$ & $4.39( \pm 0.64)$ & $4.32( \pm 0.56)$ & $\begin{array}{l}\text { Md vs. Mw, } \\
\text { Md vs. N }\end{array}$ \\
\hline
\end{tabular}

Mean $( \pm S D)$ of student responses for each statement assessed using five-point Likert scale (Very helpful $=5 ;$ Helpful $=4 ;$ Neutral $=3 ;$ Not helpful $=2 ;$ Not at all helpful =1). Md, medical cohort; $\mathrm{D}$, dentistry cohort; $\mathrm{N}$, nursing cohort; Mw, midwifery cohort.

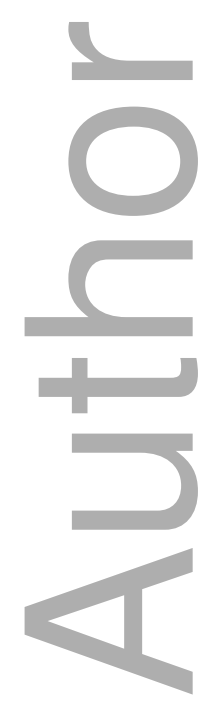




\section{University Library}

\section{- M M N E R VA A gateway to Melbourne's research publications}

Minerva Access is the Institutional Repository of The University of Melbourne

Author/s:

Pickles, K;Ivanusic, JJ;Xiao, J;Durward, C;Ryan, AB;Hayes, JA

Title:

Peer Tutoring for Anatomy Workshops in Cambodia

Date:

2019-01-01

Citation:

Pickles, K., Ivanusic, J. J., Xiao, J., Durward, C., Ryan, A. B. \& Hayes, J. A. (2019). Peer

Tutoring for Anatomy Workshops in Cambodia. ANATOMICAL SCIENCES EDUCATION, 12 (1), pp.82-89. https://doi.org/10.1002/ase.1804.

Persistent Link:

http://hdl.handle.net/11343/284231 